\title{
O jogo digital Quiz dos tecidos, as contribuições da monitoria para o ensino de Histologia e para a formação acadêmica do monitor
}

\author{
Luciano Cardoso Santos ${ }^{1}$
}

Cristina Luísa Conceição de Oliveira²

\begin{abstract}
Resumo
Relatamos o desenvolvimento de um jogo digital em um projeto de iniciação à docência da disciplina de Histologia e sua importância para formação docente e qualidade do Ensino Superior. O jogo foi criado a partir do programa Power Point da Microsoft ${ }^{\circledR}$, utilizando o recurso de linkagem de slides para os principais tecidos estudados, com média de 15 questões teórico-práticas e encaminhados aos estudantes antes das provas para revisão. Constatamos sua utilidade na compreensão dos conteúdos em Histologia e para o monitor o aprofundamento na área, autonomia, autocriticidade e autorregulação da aprendizagem, aspectos que o aproximam da carreira docente. Assim, vemos como uma alternativa para professores que desejam diversificar suas estratégias didáticas com um jogo simples e de fácil construção.

Palavras-chave: Jogo digital; Iniciação à docência; Ensino Superior; Histologia.
\end{abstract}

The digital game Quiz of the tissues, the contributions of monitoring for the teaching of histology and academic training of the teaching assistant

\begin{abstract}
We report the development of a digital game in a project of initiation to the teaching of the discipline of Histology and its importance for teacher training and quality of Higher Education. The game was created from the Microsoft ${ }^{\circledR}$ Power Point program, using the slide link feature for the main tissues studied, averaging 15 theoretical-practical questions and sent to students before the tests for review. We cite its usefulness in the understanding of contents in Histology and for the monitor the deepening in the area, autonomy, self-criticism, and self-regulation of learning, aspects that bring it closer to the teaching career. Thus, we see as an alternative for teachers who wish to diversify their didactic strategies with a simple game and easy construction.

Keywords: Digital game; Initiation to the teaching; Higher Education; Histology.
\end{abstract}

\section{Introdução}

A Histologia é um componente curricular importante em vários cursos de graduação no Ensino Superior, principalmente das Ciências Biológicas e Saúde. Como área do conhecimento científico, a histologia ${ }^{3}$ estuda os tecidos do corpo e como eles se organizam na formação dos

\footnotetext{
${ }^{1}$ Universidade Estadual de Santa Cruz, Ilhéus - Bahia, luciano.cardoso23@hotmail.com

2 Universidade Estadual de Santa Cruz, Ilhéus - Bahia, crisbio2@gmail.com

${ }^{3}$ Utilizaremos inicial minúscula quando o termo fizer referência à área do conhecimento. Quando se tratar de um componente curricular, o mesmo será escrito com inicial maiúscula.
} 
órgãos e sistemas (GARTNER; HIATT, 2003; JUNQUEIRA; CARNEIRO, 2004).

$\mathrm{Na}$ universidade relatada, Histologia é ofertada no início dos cursos e, por ser caracterizada por grande quantidade de conteúdos e elevado nível de dificuldade, há necessidade de investir em metodologias alternativas que consigam atender todos os estudantes, desenvolvendo com eles o interesse pelos conteúdos e facilitando o processo de aprendizagem. Nesse sentido, os projetos de Iniciação à Docência na modalidade de monitoria têm desempenhado funções importantes no ensino de disciplinas como Histologia (SILVA; BELO, 2010, 2012).

Esses projetos se apresentam como umas das ferramentas essenciais no processo de ensino e aprendizagem, contribuindo também para uma formação docente do monitor. Dentre as atividades que podem ser desenvolvidas com a colaboração do monitor estão os jogos digitais para as aulas e revisões fora dela. Pela flexibilidade de uso em diversas áreas do conhecimento, esses jogos podem ser instrumentos importantes para a Histologia, sobretudo nesses tempos de escassez em que lâminas histológicas e microscópios de boa qualidade são raros nas escolas e universidades públicas.

Apesar da importância do desenvolvimento de estratégias de ensino, poucos são os trabalhos voltados para o Ensino Superior e são ainda mais escassos em Histologia. A maioria dos trabalhos publicados na área, cerca de $65 \%$, tratam da implantação de estratégias virtuais de ensino para o ambiente presencial de aprendizagem e $46 \%$ destes são sobre o uso do microscópio virtual no ambiente escolar do Ensino Superior (ARAUJO; LIMA, 2016), dados que nos dão uma ideia de virtualização do ensino de Histologia.

No entanto, ainda que exista uma tendência de virtualização do ensino de Histologia, até o momento são poucos os trabalhos na literatura que relatam o uso de jogos digitais como material educacional nessa área. Sendo assim, consideramos relevante relatar uma experiência de construção e aplicação do jogo digital Quiz dos tecidos ao longo do Projeto de Iniciação à Docência, através da monitoria de Histologia, trazendo paralelamente uma discussão sobre as contribuições desse projeto para formação acadêmica do monitor.

Pensamos em uma modalidade de jogo digital que possibilitasse o ensino e/ou revisão de conteúdos, mas que não exigisse o domínio de conhecimento avançado sobre o desenvolvimento de softwares, configurando-se como uma ferramenta acessível para 
professores e licenciandos em formação que desejam utilizar estratégias alternativas em suas aulas. Iniciamos o relato com uma breve revisão de literatura sobre o ensino de Histologia, a importância da monitoria como apoio nas aulas e o uso de jogos digitais no ensino. Em seguida, caracterizaremos o projeto na universidade estudada e detalharemos o processo de construção e aplicação do jogo proposto. Por último, traremos os resultados do uso destes jogos nas aulas e nas revisões extraclasse, e nossas observações sobre a monitoria na formação acadêmica do monitor.

\section{O ensino em Histologia}

O ensino de histologia tradicional está vinculado à leitura de lâminas histológicas a partir de microscópios de luz (MIRANDA et al., 2018) e tem ganhado espaço nas discussões de temas educacionais. Isso se deve à necessidade iminente de substituição das aulas tradicionais por outras alternativas de acordo com o momento atual de escassez dos recursos na área, pois "fazse necessário um espaço físico para a montagem de um laboratório de microscopia e um acervo de preparados permanentes" (MIRANDA et al., 2018, p.428), aspecto que nem toda universidade ou escola básica consegue dispor.

Como componente curricular, houve uma modernização no seu ensino devido à coevolução com a tecnologia dos microscópios posto que, desde o seu surgimento, os seus conteúdos foram adquirindo novas abordagens e sendo refinados com o avanço tecnológico, sobretudo na qualidade das imagens produzidas (SIVIERO; OLIVEIRA, 2016). Seu uso, portanto, torna-se uma prática importante nas aulas, já que acaba atraindo a atenção dos estudantes, uma vez que os conteúdos ensinados em Histologia são essencialmente descritivos e morfológicos e isso pode contribuir para o desinteresse de parte da turma (SIVIERO; OLIVEIRA, 2016).

A princípio, os livros didáticos de histologia trazem uma sequência organizada dos conteúdos que vão desde a parte rotineira da área (histotécnica), passando pelo estudo dos tecidos fundamentais do corpo, até a sua organização em sistemas corporais. Mas uma das dificuldades que geralmente os estudantes apresentam é o fato de serem conteúdos em nível microscópico, o que intensifica o desinteresse pelos mesmos (PESSOA; MAKI; FIALHO, 2018).

Para um docente que vislumbra a construção do conhecimento por parte dos estudantes, 
ensinar histologia é um desafio, porque há necessidade de repensar suas práticas de forma a tornar suas aulas mais significantes (BASÍLIO, 2010; OLIVEIRA, 2016). Nesse aspecto, repensar a prática docente é buscar novas maneiras de ensinar, ou seja, metodologias alternativas que aumentem o interesse pela disciplina e facilitem a compreensão dos conteúdos.

\section{A monitoria como modalidade de ensino e aprendizagem no Ensino Superior}

A monitoria é uma modalidade de ensino e aprendizagem (CHAVES; VASCONCELOS, 2015; FRISON, 2016; MATOSO, 2014; NATÁRIO; SANTOS, 2010) que faz parte dos Projetos de Iniciação à Docência e do apoio ao Ensino Superior em muitas universidades no Brasil, sendo caracterizada como um instrumento para a melhoria do ensino na graduação, pois é um espaço útil para aperfeiçoar o processo de formação profissional por poder otimizar o potencial acadêmico e promover a melhoria da qualidade de ensino (NATÁRIO; SANTOS, 2010). Além disso, possibilita estabelecer novas práticas e experiências pedagógicas, objetivando a integração entre a teoria e a prática, bem como promover formação docente do monitor através da vivência com o professor e a partir das atividades desenvolvidas (LINS et al., 2009).

Indo além, Natário e Santos (2010) consideram a relevância do monitor como alguém que vivencia a situação de estudante, capta as possíveis dificuldades do conteúdo ou da disciplina e também por "apresentar mais sensibilidade aos problemas e sentimentos que o aluno pode enfrentar em situações como vésperas de avaliações, acúmulo de leituras e trabalhos, início e término de semestre, etc." (NATÁRIO; SANTOS, 2010, p.356).

Nunes (2007) menciona um "compartilhamento" com o monitor na tarefa de ajudar na resolução das dificuldades vivenciadas pelos alunos na disciplina, pois turmas numerosas dificultam o trabalho do professor. Percebe-se também a importância da monitoria no apoio emocional aos alunos, como demonstrado por Natário e Santos (2010) na investigação com monitores, antes e depois do programa, em que mais da metade dos monitores $(52,6 \%)$ ressaltaram a importância daquelas atividades voltadas ao apoio emocional. Além dessas atividades, o monitor é responsável por uma série de outras funções que vão desde a simples seleção de materiais a serem utilizados nas aulas práticas até a contribuição em desenvolver estratégias de ensino e aprendizagem.

Periódico Horizontes - USF - Itatiba, SP - Brasil - e020017 
A interação entre professores, estudantes e monitores é um requisito essencial para o desenvolvimento das atividades e melhoria na qualidade do processo de ensino e aprendizagem. No que diz respeito à formação para o ensino, a monitoria deve ser pensada englobando todo o processo, sendo necessário estabelecer um diálogo aberto com o monitor, em uma relação de confiança mútua, no qual possa ouvir suas opiniões desde a perspectiva de aluno e como elo que é entre o professor e os alunos. Essa relação tende a enriquecer o trabalho de preparação da disciplina, já que o monitor pode contribuir na preparação de material para aula (NUNES, 2007) numa relação participativa junto ao professor (NATÁRIO; SANTOS, 2010).

Na monitoria de Histologia da universidade palco desta experiência, uma das estratégias que pensamos foi a construção e aplicação de jogos digitais didáticos, uma tendência no ensino que alia educação e tecnologia.

\section{Jogos digitais e o ensino}

Os jogos estão sendo amplamente utilizados no ensino em diversas áreas do conhecimento. Existem aqueles jogos tradicionais/físicos, que podem ser construídos manualmente, utilizando uma gama de materiais e aqueles digitais ou eletrônicos, que utilizam a tecnologia dos eletrônicos como suporte para sua construção. Esses últimos têm obtido espaço nas salas de aula, sobretudo pelo reconhecimento por parte dos docentes da utilização de novas linguagens e tecnologias nas aulas (MIGUEL; MARINHO, 2018).

Esses jogos digitais podem ser criados exclusivamente com recursos tecnológicos ou podem ser oriundos de um processo de transformação de um jogo físico para uma versão digital, recebendo o nome, neste caso, de virtualização de jogos educativos (SANTOS; SILVA JÚNIOR, 2016; SANTOS; SANTANA, 2018).

Em relação ao público a que se destina este tipo de jogo, relatos apontam que não há uma exclusividade e que trazem contribuições para diferentes faixas etárias e anos escolares, desde o Ensino Fundamental, exercendo papéis em habilidades cognitivas de crianças (RAMOS; ANASTÁCIO, 2018; RAMOS; SEGUNDO, 2018), no ensino e aprendizagem para estudantes de Ensino Médio (MARTINS et al., 2018; XAVIER et al., 2017; JÚNIOR; VIEIRA, 2018), até na inclusão digital para idosos (CAMARGO, 2018). Esses relatos mostram o quão benéfico pode ser um jogo 


\section{HSF}

digital se bem explorado. Eles permitem trabalhar com variados recursos como textos, imagens, vídeos e outros, desempenhando uma função relevante já que se tornam excelentes ferramentas de auxílio ao ensino (CUNHA; CUNHA; DOMINGUES, 2016).

No ensino de Ciências, esse tipo de jogo tem sido bastante explorado, visto que a tecnologia tem se tornado um dos recursos facilitadores no ensino (CARVALHO; GUIMARÃES, 2016; SILVA; BARBOSA, 2016). Além disso, "a disponibilidade dos recursos inovadores desperta nos alunos maior interesse pelo que está sendo trabalhado. Conceitos abstratos ganham significado, e a aprendizagem acontece com mais estímulo e prazer" (SILVA; BARBOSA, 2016, p. 7).

Apesar disso, é importante o professor estar ciente de que, além de todas as potencialidades discutidas, os jogos podem apresentar desafios para os estudantes. Silva e Barbosa (2016) relatam que alguns alunos podem não ter tido acesso a aulas que utilizassem recursos de informática ou que outros podem não ter acesso a computadores em casa. Portanto, apesar de parecer ser um recurso fácil de ser trabalhado, os jogos devem ser bem pensados e seguir um rigoroso processo de planejamento (ANTUNES, 2004; RAMALHO; SIMÃO; PAULO, 2014).

\section{Caracterização do projeto}

Esta experiência foi vivenciada no Projeto de Iniciação à Docência, na monitoria de Histologia, no período de agosto de 2016 a julho de 2018. O projeto nessa universidade tem duração de um ano, podendo ser prorrogado por igual período e os discentes selecionados, via edital, recebem uma bolsa mensal do Programa de Apoio ao Ensino de Graduação (PAEG). A Tabela 1 mostra as atividades realizadas em colaboração com o monitor durante o período de atuação no projeto.

\section{O jogo digital Quiz dos tecidos - construção}

Desenvolvemos o jogo didático denominado Quiz dos tecidos durante o projeto de monitoria em Histologia. Para tanto, usamos o recurso de criação de hiperlinks do programa Power Point da Microsoft ${ }^{\oplus}$, que permite a transição de um slide a outro, definido estrategicamente em qualquer ponto do conjunto de slides da apresentação. 


\section{HSE}

Tabela 1 - Atividades realizadas pelo monitor e possíveis habilidades desenvolvidas

\begin{tabular}{|c|c|}
\hline Atividades realizadas pelo monitor & Possíveis habilidades desenvolvidas \\
\hline $\begin{array}{l}\text { Auxílio nas aulas práticas e revisão de } \\
\text { conteúdos extraclasse; }\end{array}$ & $\begin{array}{l}\text { Organização de aulas práticas, postura } \\
\text { docente e desenvoltura para explicar o } \\
\text { conteúdo de forma clara e segura; }\end{array}$ \\
\hline $\begin{array}{l}\text { Elaboração de estratégias alternativas para o } \\
\text { ensino em conjunto com o professor da } \\
\text { disciplina; }\end{array}$ & $\begin{array}{l}\text { Criatividade e diversificação das metodologias } \\
\text { para o ensino de Histologia; }\end{array}$ \\
\hline $\begin{array}{l}\text { Seleção de lâminas histológicas para aulas } \\
\text { práticas e organização das mesmas no } \\
\text { laminário do laboratório de Histologia } \\
\text { Animal; }\end{array}$ & Habilidades organizacionais e metodológicas; \\
\hline Estudo dos conteúdos teóricos e práticos. & $\begin{array}{l}\text { Aprofundamento teórico e prático para } \\
\text { melhor atuar durante as aulas de Histologia. }\end{array}$ \\
\hline
\end{tabular}

Fonte: Dados do Projeto

Primeiramente inserimos um slide introdutório contendo as regras do jogo (Figura 1A) e, em outro, a questão e as alternativas, cada uma em caixas de texto separadas (Figura 1B). Em seguida, inserimos um slide indicando o acerto (Figura 1C) e outro, na sequência, o erro (Figura 1D). O próximo passo foi criar um link de transição em cada caixa, contendo as alternativas para o slide, que indicará erro (no caso das alternativas erradas) e acerto (no caso da alternativa correta). A figura 2 exemplifica a inserção de hiperlinks para a alternativa correta. Seguimos essa mesma etapa para todas as alternativas erradas. Desse modo, quando o estudante clicar na alternativa escolhida, a apresentação será direcionada para o resultado da resposta, indicando erro ou acerto da questão.

Para dar prosseguimento ao jogo, criamos uma caixa de texto no slide Resposta certa, indicando Continue! (Figura 1C), com link para o slide que contém a próxima questão. Optamos também por criar um link do slide que indique a resposta errada (Figura 1D) para o slide anterior que contém a questão, dando oportunidade ao estudante de tentar novamente a resolução da mesma. 


\section{HSE}

Figura 1 - Jogo Quiz dos tecidos - Tecido epitelial

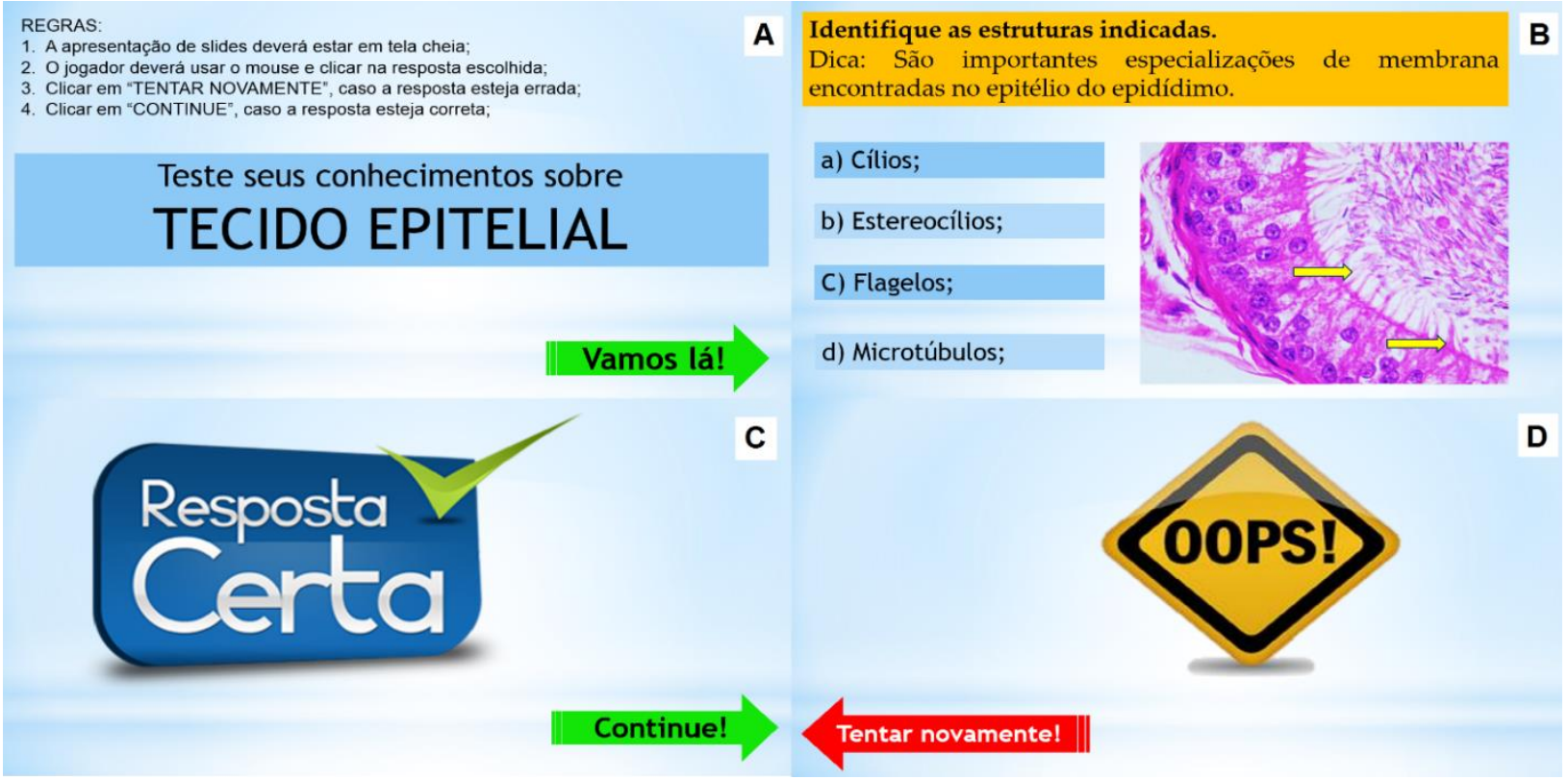

A: Apresentação e regras. B: Exemplo de questão e alternativas. C: Slide com indicação de resposta correta. D: Slide com indicação de resposta incorreta.

Fonte: Dados do Projeto

Procuramos desenvolver arquivos leves (15 questões/ 2.000-9.000 KB) pela necessidade de disponibilização via e-mail para as turmas antes da realização das provas, já que a ideia é a funcionalidade do jogo como revisão nesses momentos. Desenvolvemos arquivos para os principais tecidos estudados (epitelial, conjuntivo, muscular, adiposo e cartilaginoso) e outros, envolvendo vários conteúdos em uma versão adaptada, criada para jogar na aula, coletivamente entre professor, estudante e monitor. Retiramos os links dos slides e as questões foram passadas no aparelho de data show, lidas e respondidas oralmente pelos grupos durante a aplicação. 


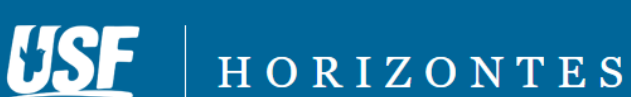

Figura 2 - Inserção de hiperlink

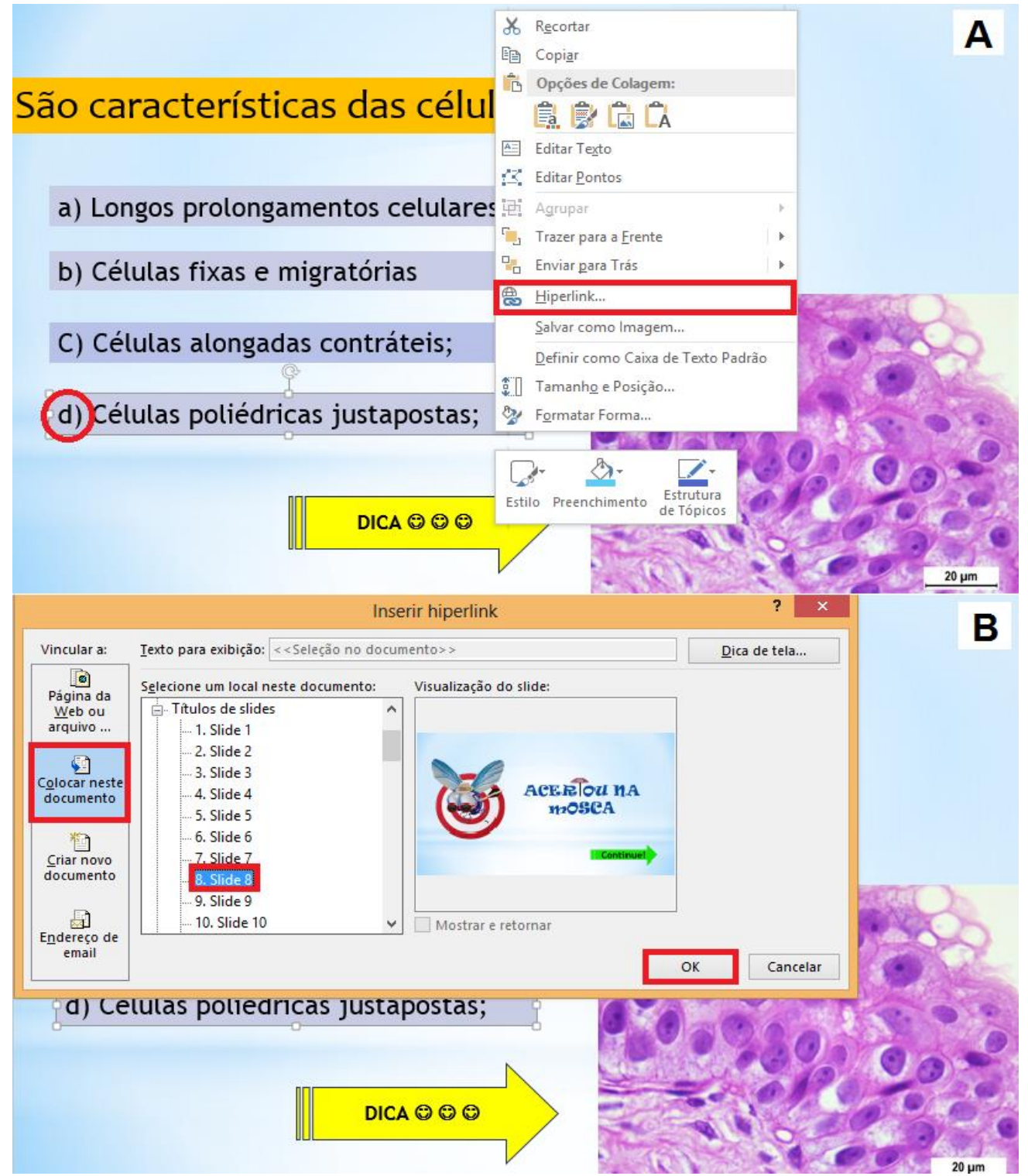

A: Seleção da caixa de texto que contém a alternativa correta com o botão direito do mouse, seguido de hiperlink.

B: Seleção do destino de transição (Colocar neste documento) + slide de indicação de resposta correta.

Fonte: Dados adaptados do Projeto

Construímos esse trabalho com base em dados gerados pela vivência na monitoria, ao longo do período de participação no Projeto e durante a utilização do jogo. Portanto os resultados trazidos são frutos de nossas observações. Para incrementar as análises, fizemos uma avaliação interna de todas as atividades realizadas no período, nessa atuação conjunta entre docente e monitor, o que nos permitiu ter mais clareza sobre as contribuições da monitoria para o ensino de Histologia e melhoria de qualidade das aulas. Incluímos nessa avaliação o uso do jogo proposto. 


\section{Resultados e discussão \\ Uso do jogo proposto}

Em conversas informais com os estudantes nas aulas seguintes à aplicação do jogo, percebemos que, mesmo sem cobrança de uso, essa ferramenta chamou atenção pela facilidade de acesso, interatividade e dinamismo em revisar os conteúdos. Para os estudantes, além dessas características relatadas, o jogo parece ter sido uma alternativa descontraída, criativa e menos cansativa para estudar antes das provas. Nesse sentido, nessa avaliação de contribuição do jogo feita ao final da monitoria, vimos que houve aprovação e indicação como alternativa potencial para se adotar na disciplina, ou seja, um retorno importante nesse momento de crise de recursos financeiros para as aulas de Histologia nas universidades.

Em relação ao uso de jogos digitais, Santos et al. (2015) também observaram retorno positivo desta ferramenta, onde obtiveram um índice de $86 \%$ de aceitação de usuários. Segundo esses autores, os jogos fazem parte de atividades diversas que são importantes para atração do encanto dos alunos e para tratar dos assuntos teóricos de forma divertida e interativa.

De fato, o uso de jogos digitais favorece a aprendizagem pelo envolvimento do ensino com o lúdico, proporcionando um momento prazeroso. Essa ideia é também compartilhada por Silva e Barbosa (2016, p.7), onde colocam que "educação lúdica, jogos, tecnologia e interatividade são termos que se encontram entrelaçados" e que os softwares são valiosos por conseguir introduzir o lúdico nos processos de ensino e aprendizagem (SILVA; BARBOSA, 2016).

Corroborando com essa ideia, Cunha, Cunha e Domingues (2016, s.p), ao investigarem os benefícios de jogos eletrônicos digitais no ensino, afirmam que eles são capazes de gerar "interatividade, motivação, desafio, fantasia e curiosidade, permitindo criar atividades mais efetivas de exploração e descoberta". Esses autores ainda acrescentam que:

Outra vantagem deste recurso é a possibilidade do aprendiz poder estabelecer o seu ritmo de aprendizagem, tendo o controle do tempo, a liberdade de escolher as condições iniciais e visualizar as diversas possibilidades de evolução. Desse modo cada aluno escolherá seu ritmo conveniente para utilizar os recursos, evitando uma sobrecarga de informações. (CUNHA; CUNHA; DOMINGUES, 2016, s.p) 


\section{HSF}

A fala desses autores diz muito sobre a nossa ideia de utilização do jogo proposto, porque o ritmo de aprendizagem é diferente entre os alunos. Por isso, também tivemos a preocupação em não cobrar o acesso, ou seja, sendo uma opção ao estudante dentro de suas possibilidades de estudo. Dessa forma, esse jogo se mostrou como uma alternativa para revisar os assuntos das aulas, complementando os meios de estudo dos estudantes. Essa flexibilidade foi observada também na possibilidade de "tentar novamente" a resolução da questão, aumentando as opções do jogo com o recurso de linkagem do programa, permitindo maior interatividade do estudante no momento da revisão.

Apresentar alternativas de revisão para os alunos em um componente curricular como Histologia é essencial para enfrentar as dificuldades geradas nessa disciplina, como o elevado número de conteúdos trabalhados e a necessidade visual que ela exige. Nesse sentido, o Quiz dos tecidos se mostra eficiente para revisar questões conceituais, bem como aspectos práticos e visuais, sendo relevante principalmente para aqueles alunos que apresentam dificuldades na identificação dos tecidos. No que diz respeito à escolha de um jogo, Ramalho, Simão e Paulo (2014) consideram que é importante este estar adequado ao conteúdo proposto para uma maior absorção dos conceitos pelo aluno.

Reafirmando a ideia de evolução conjunta entre disciplina e tecnologia, hoje se observam muitos trabalhos que demonstram o uso de outras ferramentas no ensino de Histologia, como o uso de ambientes virtuais de aprendizagem e outros meios tecnológicos (ARAÚJO; LIMA, 2016; BLAKE; LAVOIE; MILLETTE, 2003; DIAS DA SILVA; PEREIRA, 2013; HIGAZI, 2011; MONTANARI, 2016; SANTA-ROSA; STRUCHINER, 2010, 2011; SHERMAN; JUE, 2009; SIVIERO; OLIVEIRA, 2016), demonstrando a necessidade de alternativas de ensino em um contexto de carência de investimento em lâminas histológicas e microscópios.

\section{Outras contribuições da monitoria de Histologia para o ensino e para a formação acadêmica do monitor}

Para suprir as necessidades dos estudantes quanto às dúvidas, os monitores atuaram em revisões fora das aulas, geralmente nas semanas antecedentes às provas. Essas revisões possuíram caráter prático e teórico onde, além de investirmos na identificação e caracterização 
de imagens histológicas, disponibilizávamos os jogos didáticos produzidos para que os alunos revisassem os assuntos em casa.

Com relação à participação dos cursos nas atividades de revisão extraclasse, percebemos que, em alguns deles, a prática da monitoria é mais comumente utilizada e os monitores são mais requisitados, a exemplo do Curso de Medicina Veterinária que, mesmo quando não houve disponibilidade de monitor durante as aulas, os alunos procuravam; enquanto, nos demais cursos, a procura pela ajuda do monitor é menor. Silva e Belo (2012) verificaram que mais 74\% dos alunos entrevistados relataram que não procuravam o monitor devido ao "tempo disponível insuficiente", fato esse que é compreensível devido à grande quantidade de atividades em que os alunos estão envolvidos.

A participação da monitoria durante as aulas práticas contribuiu para a aprendizagem dos alunos e para a formação docente na função de monitor. Muitos estudantes têm na figura do monitor alguém próximo (NUNES, 2007; SILVEIRA; SALES, 2016), com o qual eles se sentem mais à vontade para tirar suas dúvidas. Nessas situações, o potencial disponível do monitor para o aprendizado constitui-se como um caminho mais acessível (LIRA et al., 2015).

O contato diário com os estudantes e com as situações da prática docente, desde a preparação de aulas até o acompanhamento de alunos durante o processo, permitiu-nos despertar o interesse pela carreira docente, consolidar noções de aprendizado, responsabilidades, compromisso e dedicação, características essas que, segundo Oliveira, Souza e Silva (2017), são fundamentais para a formação inicial de professores, pois tivemos a oportunidade do "fazer", sendo uma das formas de se adquirir habilidades em qualquer atividade profissional (ASSIS et al., 2006).

Como modalidade de ensino que potencializa a aprendizagem colaborativa e autorregulada (FRISON, 2016), além de despertar o interesse pela carreira docente, é considerada um instrumento de afirmação na formação inicial de professores, visto que é um privilégio por permitir descoberta da vocação, ou não, pela docência, evitando um descontentamento com a carreira escolhida, no futuro (MATOSO, 2014). Mais do que despertar o interesse pela carreira docente, a monitoria, conforme demonstraram Natário e Santos (2010), é fundamental para reafirmação e esclarecimentos sobre a profissão. Será isso mesmo que queremos para a vida?

Periódico Horizontes - USF - Itatiba, SP - Brasil - e020017 


\section{HSE}

Autocrítica e autonomia na prática docente formam outras observações importantes oriundas da monitoria, sendo essenciais como forma de autoavaliação do professor em formação e estão relacionadas com o aumento do senso de responsabilidade e ampliação do vínculo do discente-monitor-docente (OLIVEIRA; SOUZA; SILVA, 2017). Nesse aspecto, a reflexão constante sobre a própria prática é indispensável para que aconteça a melhoria do trabalho pedagógico do docente (NUNES, 2007), tornando-o responsável, a partir dessa reflexão, pelas demandas que possam surgir em sua área de atuação, observando suas limitações e habilidades, na busca incessante de aprimorá-las (LIRA et al., 2015).

Além do mais, o projeto contribuiu para o nosso processo de autorregulação de aprendizagens e dos alunos assistidos, um processo que, segundo Frison e Moraes (2010), envolve autonomia, iniciativa, planejamento, organização, características inerentes à vivência da monitoria que, por si só, exige de quem dela participa um mínimo de responsabilidade pelo próprio processo de aprendizagem. Para além, novas perspectivas acadêmicas foram vislumbradas, uma ampliação de horizontes para outras atividades da graduação e pósgraduação relacionadas à área de ensino e no campo específico da histologia.

\section{Considerações finais}

O jogo digital foi importante para a revisão de conteúdos antes das provas teóricas e práticas, visto que, ao propiciar momentos divertidos de aprendizagem com os efeitos de linkagem em Power Point, recebeu aprovação dos estudantes e indicação como alternativa eficaz para se adotar na Histologia. Isso demonstra a relevância de se investir em estratégias alternativas para o ensino na graduação, melhorando a qualidade das aulas e, no caso do Projeto de Iniciação à Docência, qualificando-nos para a função docente, com consequente melhoria da formação profissional.

Além disso, o acompanhamento da prática docente favoreceu a formação profissional, ao passo que o contato diário com os alunos nos permitiu observar quais são os desafios e as dificuldades encontradas na preparação de uma aula. A falta de investimento financeiro em lâminas, microscópios e materiais de consumo para os laboratórios, por exemplo, dificultam o processo de preparação e execução de aulas práticas. 
Dessa forma, a experiência relatada foi de suma importância para o desenvolvimento e aprimoramento das habilidades na docência, assim como a consolidação dos conteúdos trabalhados na área de histologia. Indo além, os ensinamentos adquiridos junto à professora orientadora e aos alunos monitorados integraram-se à carga intelectual, em uma revelação de novos horizontes e perspectivas acadêmicas.

\section{Referências}

ANTUNES, C. O jogo e o brinquedo na escola. In: SANTOS, M. P. Brinquedoteca - a criança e o adulto e o lúdico. Petrópolis: Vozes, 2004. p.37-55.

ARAÚJO, C. M.; LIMA, B. R. Desenvolvimento e uso integrado de recursos didáticos diversificados no ensino presencial de Histologia. Revista da SBEnBio, v.9, p.585-594, 2016.

ASSIS, F. de et al. Programa de monitoria acadêmica: percepções de monitores e orientadores. Rev. enferm. UERJ, Rio de Janeiro, v. 14, n.3, p. 391-397, 2006.

BASÍLIO, V. H. A prática pedagógica no ensino superior: o desafio de tornar-se professor. 2010. 124 f. Dissertação (Mestrado em Educação) - Universidade Federal do Piauí, Piauí, 2010.

BLAKE, C. A.; LAVOIE, H. A.; MILLETTE, C. F. Teaching medical histology at the University of South Carolina School of Medicine: Transition to virtual slides and virtual microscopes. The Anatomical Record Part B: The New Anatomist: An Official Publication of the American Association of Anatomists, v.275, n.1, p.196-206, 2003.

CAMARGO, M. B. O. $3 \stackrel{a}{a}$ idade conectada: um estudo sobre a influência do uso de jogos digitais no processo de inclusão digital para idosos. 2018. 80f. Dissertação (Mestrado em Mídia e Tecnologia) - Universidade Estadual Paulista, Faculdade de Arquitetura, Artes e Comunicação, Bauru, 2018.

CARVALHO, L. J.; GUIMARÃES, C. R. P. Tecnologia: um recurso facilitador do ensino de Ciências e Biologia. In: 8o Encontro internacional de formação de professores e 9o Fórum permanente de inovação educacional, v.9, n.1, 2016. Disponível em:

https://eventos.set.edu.br/index.php/enfope/article/view/2301/716. Acesso em: 4 jan. 2019.

CHAVES, M. D.; VASCONCELOS, T. C. A. Educação Superior: monitoria acadêmica como modalidade de ensino. Revista FAC - Faculdade Cearense, Fortaleza, v.9, n.1, p.1-10, 2015.

CUNHA, M. M.; CUNHA, S. N.; DOMINGUES, A. S.O. L. Contribuição dos textos, imagens, recursos audiovisuais, mapas conceituais e jogos eletrônicos no processo de explicação de 
conteúdos. In: 8o Encontro internacional de formação de professores e 9o Fórum permanente de inovação educacional, v.9, n.1, 2016. Disponível em:

https://eventos.set.edu.br/index.php/enfope/article/view/1921/686. Acesso em: 4 jan. 2019.

DIAS DA SILVA, M. A.; PEREIRA, A. C. Utilização das TIC no ensino complementar da histologia nas faculdades de odontologia do estado de São Paulo. Scientia Plena, Sergipe, v.9, n.10, p.1-7, 2013.

FRISON, L. M. B. Monitoria: uma modalidade de ensino que potencializa a aprendizagem colaborativa e autorregulada. Pro-Posições, São Paulo, v.27, n.1, p.133-153, 2016.

FRISON, L. M. B.; MORAES, M. A. C. As práticas de monitoria como possibilitadoras dos processos de autorregulação das aprendizagens discentes. Poíesis Pedagógica, Goiás, v.8, n.2, p.144-158, 2010.

GARTNER, L. P.; HIATT, J. L. Tratado de Histologia em cores. 2. ed. Rio de janeiro: Guanabara Koogan, 2003.

HIGAZI, T. B. Use of interactive live digital imaging to enhance histology learning in introductory level anatomy and physiology classes. Anat Sci Educ, v.4, p.78-83, 2011. DOI:

https://doi.org/10.1002/ase.211. Disponível em:

https://onlinelibrary.wiley.com/doi/pdf/10.1002/ase.211. Acesso em: 1 maio 2019.

JUNQUEIRA, L. C.; CARNEIRO, J. Histologia Básica. 10. ed. Rio de Janeiro: Guanabara Koogan, 2004.

LINS, L. F. et al. A importância da monitoria na formação acadêmica do monitor. In: Jornada de ensino, pesquisa e extensão da UFRPE, 2009. Recife. Anais Jepex: UFRPE, Recife, 2009, 2p. Disponível em: http://www.eventosufrpe.com.br/jepex2009/cd/resumos/r0147-1.pdf. Acesso em: 14 fevereiro 2019.

LIRA, M. O. et al. Contribuições da monitoria acadêmica para o processo de formação inicial docente de Licenciandos em Ciências Biológicas da UEPB. In: Il Congresso Nacional de Educação, 2015.Campina Grande. Anais. Disponível em:

http://www.editorarealize.com.br/revistas/conedu/trabalhos/TRABALHO_EV045_MD1_SA18_I D3045_08092015215307.pdf. Acesso em: 14 abril 2018.

MARTINS, V. C. C. et al. Tecnologias digitais: criação e utilização de mídias sociais como ferramenta educacional para a temática ambiental e o ensino de ciências. Revista Brasileira de Educação Ambiental, São Paulo, v.13, n.1, p.190-206, 2018.

MATOSO, L. M. L. A importância da monitoria na formação acadêmica do monitor: um relato de experiência. CATUSSABA, Rio de Janeiro, v.3, n.2, p.77-83, 2014. 
MIGUEL, A.; MARINHO, C. R. M. S. Jogos digitais no ensino de História: o caso Dois de Julho: tower defense. Redin-Revista Educacional Interdisciplinar, Rio Grande do Sul, v.7, n.1, p.1-10, 2018.

MIRANDA, E. J. et al. Atlas Digital como Ferramenta de Apoio ao Estudo da Histologia e Patologia. Revista de Ensino, Educação e Ciências Humanas, Paraná, v.18, n.4, p.428-431, 2018. DOI: http://dx.doi.org/10.17921/2447-8733.2017v18n4p428-431. Disponível em: http://revista.pgsskroton.com.br/index.php/ensino/article/view/4321. Acesso em: 4 jan. 2019.

MONTANARI, T. Recursos virtuais para o ensino presencial e remoto de Histologia. RENOTE, Rio Grande do Sul, v.14, n.2, 2016. DOI: https://doi.org/10.22456/1679-1916.70635. Disponível em: https://www.seer.ufrgs.br/renote/article/view/70635/40061. Acesso em: 26 jun. 2018.

NATÁRIO, E. G.; SANTOS, A. A. A. dos. Programa de monitores para o ensino superior. Estudos de Psicologia, São Paulo, v.27, n.3, p.355-364, 2010.

NUNES, J. B. C. Monitoria acadêmica: espaço de formação. In: SANTOS, M. M.; LINS, N. M. (Org) A monitoria como espaço de iniciação à docência: possibilidades e trajetórias. Natal: EDUFRN, 2007. p.45-58.

OLIVEIRA, G. C.; SOUZA, F. P.; SILVA, E. N. Papel da monitoria na formação acadêmica: um relato de experiência. Revista de Pesquisa Interdisciplinar, Paraíba, v.2, n.2, p.924-926, 2017. DOI: http://dx.doi.org/10.24219/rpi.v2i2.367. Disponível em:

http://revistas.ufcg.edu.br/cfp/index.php/pesquisainterdisciplinar/article/view/367/pdf. Acesso em: 26 jun. 2018.

OLIVEIRA, M. I. B. et al. Uma proposta didática para iniciar o ensino de Histologia na educação básica. Revista Ciência em Extensão, São Paulo, v.12, n.4, p.71-82, 2016.

PESSOA, F. B.; MAKI, C. S.; FIALHO, M. C. Q. Estratégias pedagógicas para o ensino de Citologia e Histologia para alunos do Ensino Médio. Revista Ciência em Extensão, São Paulo, v.14, n.2, p.138-146, 2018.

RAMALHO, J. E.; SIMÃO, F.; PAULO, A. B. D. Aprendizagem por meio de jogos digitais: um estudo de caso do jogo animal crossing. Ensaios Pedagógicos, São Paulo, v.8, p.1-13, 2014. Disponível em: <http://www.opet.com.br/faculdade/revista-pedagogia/pdf/n8/artigo-4.pdf>. Acesso em: 8 jan. 2019.

RAMOS, D. K.; ANASTÁCIO, B. S. Habilidades cognitivas e o uso de jogos digitais na escola: a percepção das crianças. Educação Unisinos, Rio Grande do Sul, v.22, n.2, p.214-223, 2018. DOI: 10.4013/edu.2018.222.11. Disponível em:

http://revistas.unisinos.br/index.php/educacao/article/view/edu.2018.222.11/60746214. Acesso em: 4 jan. 2019. 
RAMOS, D. K.; SEGUNDO, F. R. Jogos Digitais na Escola: aprimorando a atenção e a flexibilidade cognitiva. Educação \& Realidade, v.43, Rio Grande do Sul, n.2, p.531-550, 2018. DOI: 10.1590/2175-623665738. Disponível em: http://www.redalyc.org/articulo.oa?id=317254724009. Acesso em: 4 jan. 2019.

SANTA-ROSA, J. G. S.; STRUCHINER, M. Design participativo de um ambiente virtual de aprendizagem de histologia. Revista Brasileira de Pesquisa em Educação em Ciências, Minas Gerais, v.10, n.2, 2010.

SANTA-ROSA, J. G. S.; STRUCHINER, M. Tecnologia educacional no contexto do ensino de histologia: pesquisa e desenvolvimento de um ambiente virtual de ensino e aprendizagem. Revista Brasileira de Educação Médica, Rio de Janeiro, v.35, n.2, p.289-298, 2011.

SANTOS, J. W. R. et al. Bioquiz: jogo eletrônico de Biologia para o Ensino Médio. Revista UFG, Goiás, v.15, n.16, p.44-60, 2015. DOI: https://doi.org/10.5216/revufg.v15i16.48532. Disponível em: https://www.revistas.ufg.br/revistaufg/article/view/48532/23837. Acesso em: 9 fev. 2019.

SANTOS, W. O. dos; SANTANA, S. J. Os Jogos Digitais São Realmente Melhores que os Jogos Tradicionais para Ensinar Matemática? Uma Análise sob a Concentração dos Estudantes. RENOTE, Rio Grande do Sul, v.16, n.1, 2018. DOI: https://doi.org/10.22456/16791916.85906. Disponível em: https://www.seer.ufrgs.br/renote/article/view/85906/49296. Acesso em: 9 fev. 2019.

SANTOS, W. O. dos; SILVA JUNIOR, C. G. da. Virtualização de Jogos Educativos: Uma Experiência no Ensino de Matemática. Revista Brasileira de Informática na Educação, Rio Grande do Sul, v.24, n.2, p.108-122, 2016. DOI: 10.5753/RBIE.2016.24.02.108. Disponível em: https://www.researchgate.net/profile/Wilk_Oliveira_Dos_Santos/publication/311567187_Virt ualizacao_de_Jogos_Educativos_Uma_Experiencia_no_Ensino_de_Matematica/links/584ee288 08aecb6bd8d0238c.pdf. Acesso em: 20 abr. 2019.

SHERMAN, S. C.; JUE, C. K. Pedagogical methods for teaching histology in anatomy and physiology courses. HAPS Educ, v.14, p.50-55, 2009.

SILVA JÚNIOR, J. C. A.; VIEIRA, V. S. Jogos digitais de citologia para os alunos do ensino médio. Cadernos UniFOA, Rio de Janeiro, v.5, n.1, p.138, 2018. Disponível em:

file://C:/Users/Win\%208/Downloads/2517-7979-1-SM.pdf. Acesso em: 14 fev. 2019.

SILVA, R. L. J. da; BARBOSA, A. R. Ensino de Ciências e Tecnologias Digitais: desafios e potencialidades. Ciclo Revista, Goiás, v.1, n.2, p.5-10, 2016. Disponível em: https://www.ifgoiano.edu.br/periodicos/index.php/ciclo/article/view/218/131. Acesso em: 4 jan. 2019.

SILVA, R. N.; BELO, M. L. M. Atuação do monitor na construção de recurso didático para o ensino-aprendizagem em Histologia. Revista SBEnBio, v.3, p.2243-2251, 2010. 
SILVA, R. N.; BELO, M. L. M. Experiências e reflexões de monitoria: contribuição ao ensinoaprendizagem. Scientia Plena, Sergipe, v.8, n.7, p.1-6, 2012.

SILVEIRA, E.; SALES, F. A importância do Programa de Monitoria no ensino de Biblioteconomia da Universidade do Estado de Santa Catarina (UDESC). InCID: Revista de Ciência da Informação e Documentação, São Paulo, v.7, n.1, p.131-149, 2016.

SIVIERO, F.; OLIVEIRA, S. F. Modernização do Ensino de Biologia Tecidual. Revista de Graduação USP, São Paulo, v.1, n.1, p.35-40, 2016.

XAVIER, A. R.et al. Uso de objetos educacionais no ensino de Ciências Biológicas: alternativa metodológica para o Ensino Médio. Interdisciplinary Scientific Journal, v.4, n.4, p.16-36, 2017. D.O.I: http://dx.doi.org/10.17115/2358-8411/v4n4a2. Disponível em:

http://revista.srvroot.com/linkscienceplace/index.php/linkscienceplace/article/view/415/208. Acesso em: 1 mar. 2019.

Recebido em maio 2019.

Aprovado em janeiro 2020. 